\title{
Bioanalysis
}

\section{Quantitative analysis of methyl and propyl parabens in neonatal DBS using LC-MS/MS}

\begin{abstract}
Aim: Excipients are used to overcome the chemical, physical and microbiological challenges posed by developing formulated medicines. Both methyl and propyl paraben are commonly used in pediatric liquid formulations. There is no data on systemic exposure to parabens in neonates. The European Study of Neonatal Exposure to Excipients project has investigated this. Results \& methodology: DBS sampling was used to collect opportunistic blood samples. Parabens were extracted from the DBS and analyzed using a validated LC-MS/MS assay. Discussion \& conclusion: The above assay was applied to analyze neonatal DBS samples. The blood concentrations of parabens in neonates confirm systemic exposure to parabens following administration of routine medicines.
\end{abstract}

First draft submitted: 2 February 2016; Accepted for publication: 13 April 2016; Published online: 23 May 2016

Keywords: acceptable daily intake $\bullet$ DBS $\bullet$ excipient kinetics $\bullet$ internal standard $\bullet$ parabens - solid phase extraction

Pediatric liquid formulations contain the active pharmaceutical ingredient and excipients. To overcome the physical, chemical and microbiological challenges in these formulations, excipients are normally used. The commonly used excipients in pediatric formulations are methyl (MPB) and propyl paraben (PPB), which are the methyl and propyl esters of p-hydroxybenzoic acid, respectively Figure 1 . Acceptable daily intake of MPB has been established for adults at 10 $\mathrm{mg} / \mathrm{kg}$ bw/day [1]. No acceptable daily intake has been assigned to PPB. Until recently, there has been no data on systemic exposure to parabens in human neonates. There are long standing concerns about parabens relating to the possibility of oestrogenic effects and cell physiology, which could cause adverse long-term outcomes. Previous work assessments of exposure to excipients in neonates have been based on estimates of intake [2]. In order to move from theoretical extrapolations of exposure based on estimates of intake, the European Study of Neonatal Exposure to Excipients (ESNEE) project conducted studies within a clinical environment to define systemic exposure of MPB and PPB in neonates. An observational study of systemic concentrations of parabens in human neonates could provide a good indication as to the range of exposures in neonates during their routine clinical care.

To study the PK of drugs, the biological matrix of choice is blood plasma. Quantification of drugs or excipients in the blood samples taken from neonates is very challenging. The total circulating volume of blood [3] in preterm and term neonates is very low $(80-90 \mathrm{ml} / \mathrm{kg}$ or $\sim 45-360 \mathrm{ml})$. The DBS sampling approach was used in this study for clinical and ethical reasons, as multiple plasma sampling (which is a prerequisite for PK studies) is not always possible in this age range. Emmons and Rowland have discussed the application of DBS to study PK [4].
Shirish Yakkundi*,1, Hussain Mulla², Hitesh Pandya ${ }^{3}$, Mark A Turner ${ }^{4}$ \& James McElnay ${ }^{1}$

'Clinical \& Practice Research Group, School of Pharmacy, Queen's University Belfast, 97 Lisburn Road, Belfast BT9 7BL Northern Ireland, UK

${ }^{2}$ Department of Pharmacy, Glenfield Hospital, University Hospitals of Leicester, Leicester, UK

${ }^{3}$ Department of Infection, Immunity \& Inflammation, University of Leicester, Leicester, UK

${ }^{4}$ Department of Women's \& Children's Health, Institute of Translational Medicine, University of Liverpool, Liverpool, UK

*Author for correspondence:

Fax: +44 2890247794

s.yakkundi@qub.ac.uk 


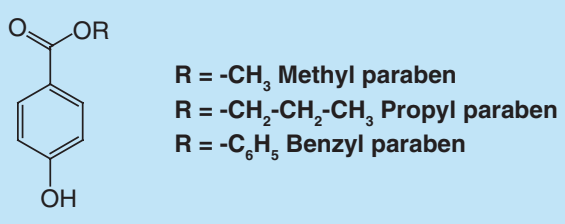

Figure 1. Chemical structures of parabens used in the study.

Parabens have been quantified in a range of matrices using high performance liquid chromatography coupled with the following detectors; UV [5-8], photodiode array [9] and MS/MS [10-22]. GC has also been used with free induction decay [23], TOF [24] and MS [25] as has thin layer chromatography [10]. The biological matrices used included urine [5,12,14,16,18-19,22], serum [14,17], seminal plasma [14], breast tissue [10], placental tissue [15], saliva [6], breast milk [13,21] and rat plasma [20]. Parabens have also been determined in water $[24,25]$, personal care products $[6,8,11,23,26]$ and pharmaceutical preparations $[7,9]$.

Several sample preparation methodologies have been reported to facilitate the extraction of parabens from the above tissues. These approaches include SPE [1213,19,22,24], LLE [8,14,16,18,20-21,23], dispersive LLE [17], solvent extraction $[5-6,10,15,26]$, stir-bar sorptive extraction [25], super critical extraction [11] and simple protein precipitation [20].

The first person to use the DBS technology in infants to screen in-born errors of metabolism was $R$ Guthrie [27]. In comparison to the venous sampling, the DBS technique has proven to be minimally invasive. This sampling technique can be used at home or in the clinical settings, as it requires less training. Storing and shipping these samples in dried form is very safe $[28,29]$. Our group has previously reported similar applications involving DBS [30-34] to develop bioanalytical methods.

Herein, we report the development and validation of an assay to support the clinical measurement of MPB and PPB from DBS by LC-MS/MS. This is the first report describing the quantification of parabens in the DBS samples.

\section{Materials \& methods Chemicals \& reagents}

Analytical grade reagents and chemicals were used for all the extractions and assays. Methyl, propyl and benzyl paraben (BPB) (Figure 1) were purchased from Sigma (Poole, UK). BPB was used as an internal standard (IS). HPLC grade solvents and water, buffers, Oasis ${ }^{\circledR}$ HLB cartridges $(1 \mathrm{cc} / 30 \mathrm{mg}$ ) were all purchased as mentioned in our previous publica- tion [32]. The School of Pharmacy Ethical Committee (013PMY2009) approved the collection of blank blood from healthy human volunteers

Ahlstorm 226 (Guthrie cards) together with storage pouches were purchased from 3M Security Systems Division (Oldham, England). A $8 \mathrm{~mm}$ single hole punch (2700-62) used to cut out the DBS disks from the cards was purchased from Darice, Strongsville, Ohio, USA. Zip-loc bags, silica gel pouches and freezer storage lunch boxes were procured from the Amazon website. Manual SPE manifold (Waters Dublin, Ireland) was used for SPE. For solvent evaporation, Zymark Turbo Vap ${ }^{\circledR}$ LV Evaporator workstation (Zymark, Runcorn, UK) was used. Eppendorf tubes $2 \mathrm{ml}$ (Sarstedt, Numbrecht, Germany) were used for the initial extraction of the DBS samples. Stuart rotator SB2 and vortex mixer SA8 (Bibby Scientific, Staffordshire, UK) were used to mix the spiked blood and vortex samples, respectively.

\section{Chromatography}

Waters Alliance HT system 2795 (Waters, Dublin) was the LC system used for separation. A XBridge ${ }^{\mathrm{TM}}$ C18 column $(3.5 \mu \mathrm{m}, 4.6 \times 100 \mathrm{~mm})$ was used along with XBridge $(3.5 \mu \mathrm{m}, 4.6 \times 20 \mathrm{~mm})$ guard column, which had a matching chemistry. Both the columns were maintained at $25^{\circ} \mathrm{C}$ during the chromatographic separation. Mobile phase consisted of methanol/5 mM ammonium acetate $(99: 1 \mathrm{v} / \mathrm{v})$ with a flow rate of $0.3 \mathrm{ml} / \mathrm{min}$.

\section{Mass spectrometry}

The above LC system was hyphenated to Waters Micromass Quattro Premier ${ }^{\mathrm{TM}}$ tandem quadrupole (Waters, Manchester, UK).

The MS conditions for the electrospray negative ion mode (ESI-) were optimized at the following conditions: Cone gas (nitrogen) $75 \mathrm{l} / \mathrm{h}$, desolvation gas (nitrogen) $800 \mathrm{l} / \mathrm{h}$, desolvation temperature $400^{\circ} \mathrm{C}$, source temperature $145^{\circ} \mathrm{C}$ and capillary voltage $2.60 \mathrm{~V}$. Argon gas was used as the collision gas.

The following multiple reaction monitoring transitions were setup for quantitation of each ion:

- MPB: For molecular ion, quadrupole 1 was set at $\mathrm{m} / \mathrm{z} 150.90$ and for product ion quadrupole 2 at $\mathrm{m} / \mathrm{z} 91.80$. The cone voltage and collision energy for the product ion, the detector was set at $20 \mathrm{~V}$ and $25 \mathrm{eV}$, respectively.

- PPB: For molecular ion, quadrupole 1 was set at $m / z 178.96$ and for product ion quadrupole 2 at $\mathrm{m} / \mathrm{z}$ 91.80. The cone voltage and collision energy for the product ion, the detector was set at $23 \mathrm{~V}$ and $26 \mathrm{eV}$, respectively. 
- BPB (IS): For molecular ion, quadrupole 1 was set at $m / z 227.00$ and for product ion quadrupole 2 at $m / z 91.80$. The cone voltage and collision energy for the product ion, the detector was set at $25 \mathrm{~V}$ and $24 \mathrm{eV}$, respectively.

For each ion the dwell time was set at $0.05 \mathrm{~s}$.

\section{Software}

MassLynx ${ }^{\text {TM }} 4.1$ Software was used to control the LC system and the mass spectrometer and the data were processed using QuanLynx Application Manager.

\section{Sample preparation}

Preparation of spiked standards \& working solutions

The stock $(1 \mathrm{mg} / \mathrm{ml})$ and working standards for MPB, $\mathrm{PPB}$ and $\mathrm{BPB}$ were prepared in methanol. The working calibration standards of MPB and PPB (prepared and mixed in the same pot) were prepared at the concentrations 50, 25, 20, 5, 4, 2.5 and $1 \mu \mathrm{g} / \mathrm{ml}$. Similarly MPB and PPB (prepared and mixed in the same pot) working quality control (QC) standards were prepared separately at concentrations 40, 10, 2 and $1 \mu \mathrm{g} / \mathrm{ml}$. A $5 \mathrm{ng} / \mathrm{ml}$ working standard of IS was prepared. All the above solutions were stored at $4^{\circ} \mathrm{C}$ and were brought to $\left(20^{\circ} \mathrm{C}\right)$ room temperature, before use.

Spiking of whole blank blood for the preparation of calibration \& QC samples

Calibration standards: to $980 \mu \mathrm{l}$ of whole blood, $20 \mu \mathrm{l}$ of the appropriate MPB + PPB working standard solution containing $50,25,20,5,4,2.5$ and $1 \mu \mathrm{g} / \mathrm{ml}$ was spiked to give final concentrations of $1000,500,400$, $100,80,50$ and $20 \mathrm{ng} / \mathrm{ml}$.

Similarly, the QC samples at concentration $20 \mathrm{ng} / \mathrm{ml}$ (LOQ), $40 \mathrm{ng} / \mathrm{ml}$ (low QC), $200 \mathrm{ng} / \mathrm{ml}$ (middle QC) and $800 \mathrm{ng} / \mathrm{ml}$ (high QC) were prepared by spiking $20 \mu \mathrm{l}$ of MPB working solutions $1,2,10$ and $40 \mu \mathrm{g} / \mathrm{ml}$ to $980 \mu \mathrm{l}$ of whole blood, respectively.

\section{Blood spotting}

Spiked blood was mixed very slowly by rotating for $45 \mathrm{~min}$ at room temperature before spotting. This was done for the equilibration of the parabens in the blood. The blood spots were prepared by accurately transferring $15 \mu \mathrm{l}$ of the spiked blood, using a calibrated pipette from both (calibration and QC standards) onto Ahlstorm 226 cards. The samples were dried for $3 \mathrm{~h}$ at room temperature in the dark (cupboard) and then placed in zip lock bags along with silica gel pouches. The cards were then stored in polypropylene freezer storage sealed containers at $-20^{\circ} \mathrm{C}$ until analysis.

\section{Extraction procedure for DBS samples}

The DBS samples were brought to room temperature before analysis. An $8 \mathrm{~mm}$ disk was punched from the card, wherein the complete blood spot was captured. This was then transferred to $2 \mathrm{ml}$ eppendorf tubes and extracted by addition of $1 \mathrm{ml}$ of methanolic BPB (IS) solution $(5 \mathrm{ng} / \mathrm{ml})$, followed by vortex mixing for 30 min. The extracts were then evaporated to dryness under nitrogen on the Zymark Turbovap at $37^{\circ} \mathrm{C}$ and reconstituted with $1 \mathrm{ml}$ of milli-Q water, followed by vortex mixing for $1 \mathrm{~min}$. The samples were further cleaned using SPE Oasis ${ }^{\circledR}$ HLB cartridges. The clean up was done as mentioned in our previous publication [32] and reconstituted in $200 \mu \mathrm{l}$ of methanol. A volume of $20 \mu \mathrm{l}$ was injected with the auto sampler temperature set at $15^{\circ} \mathrm{C}$.

\section{ESNEE clinical study \& sample collection}

The Ethical approval for the ESNEE study was granted by National Research Ethics Service Committee North West - Greater Manchester North, ref no $11 / \mathrm{NW} / 0665$. The samples in Estonia were collected under the ethical approval from the University of Tartu (210/T-11). DBS sampling was used to collect opportunistic blood samples $(15 \mu \mathrm{l})$ from the neonates who had been administered parabens containing formulations. A total number of 927 DBS samples were collected from 196 neonates from 4 UK and 1 site from Estonia. The study was registered with International Standard Randomised Controlled Trial (ISRCTN 31837223).

\section{Method validation}

US FDA guidelines [35] were applied for all the validation experiments.

Six different sources of the blank DBS samples were used to determine the selectivity. To assess linearity, five calibration curves were analyzed on five consecutive days. The slopes, intercepts, correlation (r), the weighting factor $\left(1 / \mathrm{X}^{2}\right)$ fitted for the calibration curves by least-squares linear regression and the LOQ were all calculated as previously reported [32]. Accuracy (\%RE) and precision (\%RSD) were calculated by the analyzing five replicate sets on five separate occasion, of each of the four concentrations $(20,40,200$ and $800 \mathrm{ng} / \mathrm{ml})$ of the QC samples.

The matrix effect (ME) of parabens and IS was monitored at three different concentrations (20, 200, $800 \mathrm{ng} / \mathrm{ml}$ ) and was calculated by comparing the responses from postextracted spiked samples to the pure solutions. The ratio $<85 \%$ or $>115 \%$ implies an exogenous $\mathrm{ME}$, if the ratio equals to 100 , it implies the absence of ME. Whereas, ME (\%) below or above 100 indicates ion suppression or enhancement, respectively. 
The MS response (pre-extracted to postextracted spiked sample) into a blank matrix was compared with, to determine recovery. Stability of MPB, PPB and IS in stock solution was tested at the storage temperature of $4^{\circ} \mathrm{C}$ (for 1,3 and 6 months) and stability of the stock solutions was tested at room temperature for upto $24 \mathrm{~h}$ at $20^{\circ} \mathrm{C}$. This was done by comparing the area response with those of freshly prepared stock solution. Stability of the spiked DBS samples stored at $-20^{\circ} \mathrm{C}$ was assessed over a period of $24 \mathrm{~h}, 1,3,6$ months and 1 year. For this, freshly spiked DBS samples were extracted and the ratio of peak areas (parabens to IS) was compared with the stored DBS samples. Since this was the first time any study was carried out to analyze these parabens in the DBS, it was collectively decided by the clinicians and the analysts that the samples (both spiked and patient) will be stored at $-20^{\circ} \mathrm{C}$ on the hospital premises as well as on the analytical laboratory site, until analysis. These samples were very precious, as the number of spots available for the analysis from the neonates were limited.

\section{Blood plasma partitioning of parabens}

The blood plasma partitioning for both the parabens was performed as per the protocol described by Yu et al. [36]. Two concentrations were chosen 20 and $500 \mathrm{ng} / \mathrm{ml}$ for the experiment. Both, spiked reference plasma and the whole blood plasma were incubated at $37^{\circ} \mathrm{C}$ for $1 \mathrm{~h}$ and sampling was done at $0,10,30$ and $60 \mathrm{~min}$. These samples were then analyzed. The blood plasma ratio was calculated using the equation below. Hematocrit of the blood was measured as soon as it was collected from healthy volunteers.

$$
\mathrm{K}_{\mathrm{RBC} / \mathrm{PL}}=\frac{1}{\mathrm{H}} \times \frac{\mathrm{I}_{\mathrm{REF} \mathrm{PL}}}{\mathrm{I}_{\mathrm{PL}}-1}+1
$$

where I REF PL is instrument response for Reference plasma and $I_{P L}$ is instrument response for whole blood plasma (equilibrating plasma) and $\mathrm{H}$ is the hematocrit.

\section{Results \& discussion Extraction}

Extraction of parabens from the DBS samples was optimized using different solvents or solvent mixtures such as $100 \%$ methanol, $100 \%$ water, methanol/water (25, 50 and 75\%), 100\% acetonitrile and acetonitrile/water (25, 50 and $75 \%)$. Spiked DBS samples $(20,100$ and $800 \mathrm{ng} / \mathrm{ml})$ were extracted in each of the solvents/solvent mixtures for a period of 15, 30, 45, 60, 75, 90 and $105 \mathrm{~min}$. Extracted samples at each time point were analyzed. Results showed that methanol was the best solvent and that 30 min was sufficient to extract the parabens present in the samples.
$\mathrm{BPB}$ is structurally and chemically similar to MPB and PPB, hence was used as an IS. No stable-isotope labeled IS was used. SPE was used as a sample cleanup step, to reduce the ME and any interference arising from the endogenous species present in the matrix. The SPE clean-up also showed a two-fold increase in sensitivity of MPB and PPB.

\section{Metabolites, chromatography \& selectivity}

The chromatography showed no interference or ME in both (spiked and patient samples) at the retention times of IS and parabens. The main metabolite of the parabens is p-hydroxy benzoic acid $(\mathrm{m} / \mathrm{z}$ 138.12). No interference from this metabolite was seen at the multiple reaction monitorings of $\mathrm{MPB}, \mathrm{PPB}$ and $\mathrm{BPB}$ (IS), as the molecular ions were set for $m / z 150.90$, 178.96 and 227.00, respectively, for quadrupole 1 . Some patient samples showed a peak Figure 2, which eluted approximately $1 \mathrm{~min}$ before both the parabens. Some drug metabolites or ISs can undergo fragmentation in the source of the mass spectrometer. These substances should be well-separated chromatographically from the parent drug before they reach the ion source for proper quantification. The peak seen in Figure 2 was well separated and was identified as a glucuronide metabolite of the two parabens. Glucuronidation is a common biotransformation mechanism in drug metabolism. It is a well-known phenomenon, that glucuronides undergo in-source dissociation in both positive and negative electrospray ionization. This is mainly induced by cone voltage, due to which the resulting product ions have the same $\mathrm{m} / \mathrm{z}$ values of precursor ions of the parent analyte [37,38]. Chromatographically if the glucuronide and its parent are not separated, this would interfere with the quantitation, but in our case both of them were well separated and did not hinder the quantitation.

The aim of this observational study was to look at the circulating concentrations of the parent parabens (MPB and PPB) in the neonatal blood samples and hence no attempt was made to quantify these metabolites.

\section{Linearity, limit of quantification, imprecision \& recovery}

The LOQ for both the parabens was calculated at $20 \mathrm{ng} / \mathrm{ml}$. Calibration plots of both the parabens in DBS samples were constructed using weighted $\left(1 / \mathrm{X}^{2}\right)$ linear regression. The $\%$ deviation for each calibration points was less than $10 \%$. Quanlynx software was used to perform the quantification of the parabens. The calibration curves for both the parabens were linear over the range $0-1000 \mathrm{ng} / \mathrm{ml}$ and a mean $\mathrm{r}^{2}=0.995$ $\pm 0.003(n=5)$. For MPB the mean slope was 0.001 


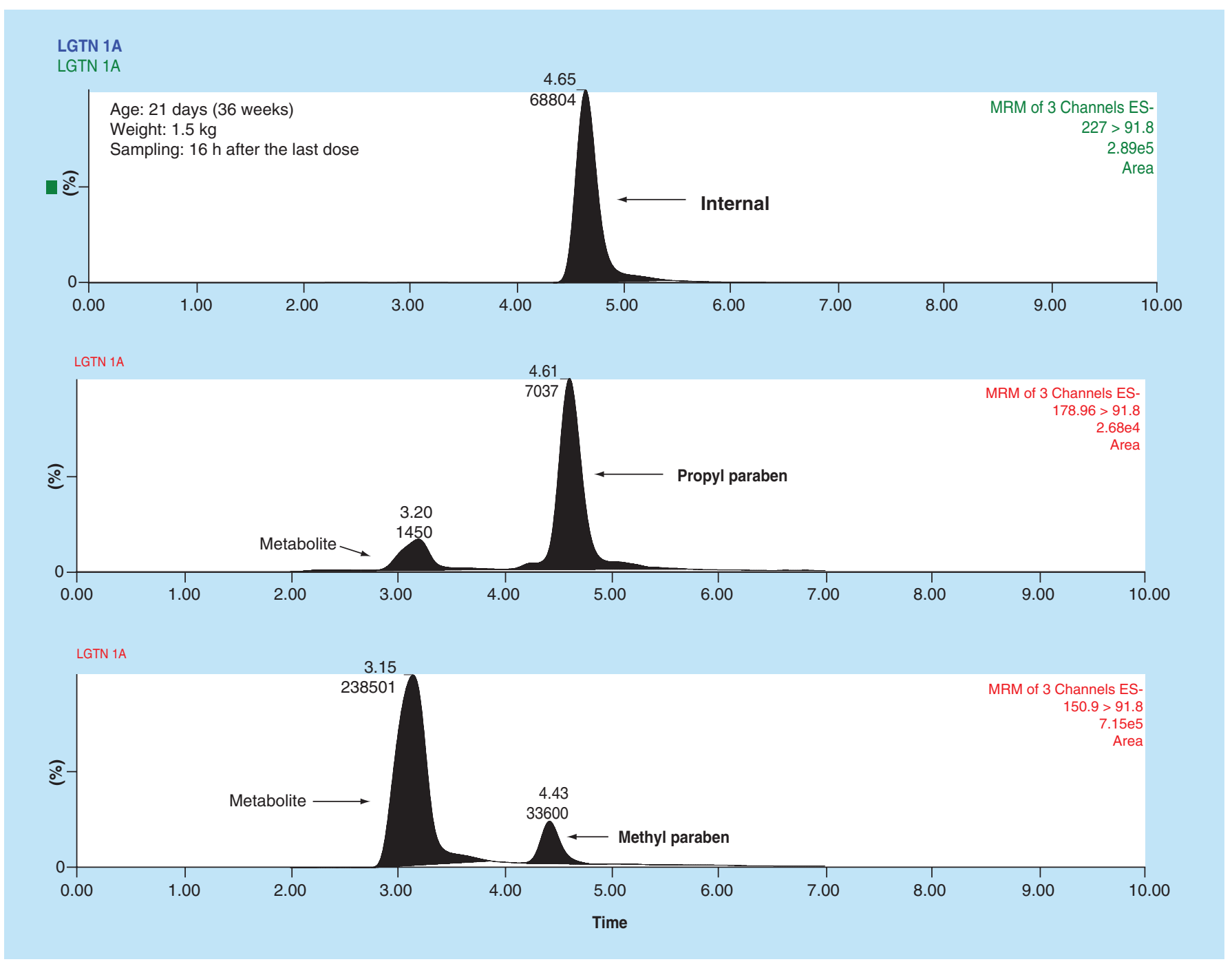

Figure 2. Chromatogram of a preterm neonate.

and intercept was 0.002 , similarly for PPB it was 0.014 and 0.003 , respectively.

There was no carryover seen during the analysis, the calibration curve and the QC's passed the FDA validation criteria [35]. The number of spots available per neonate were 1 or 2 (3, 4 in rare cases), hence the incurred sample reanalysis could not be performed. Based on our pilot study, the clinical data and dosage information, we had an estimation of range of concentrations in the samples, which fell within the calibration curve, hence the dilution test was not performed.

The validation data (inter- and intra-day) for MPB are shown in Table 1 and PPB in Table 2. The data obtained were within the FDA guidelines [35]. Inter- and intra-day variations for both the parabens were established by the analysis of five replicate sets of each of the four concentrations $(20,40,200$ and $800 \mathrm{ng} / \mathrm{ml}$ ) of the QC samples on five separate occasions. The interday imprecision was between 1.1 and $3.4 \%$ for MPB and 1.1 and $4.3 \%$ for PPB. The intraday imprecision was between 0.05 and $0.1 \%$ for MPB and 0.02 and $0.14 \%$ for PPB. The accuracy for both the parabens was well within $\pm 15 \%$. The recovery of both the parabens and IS from DBS was approximately $75 \%$.

\section{Matrix effect}

The reproducibility and accuracy of the assay may get affected due to coeluting, endogenous compounds from the matrix, which will indirectly affect the outcome of the kinetic data, hence the FDA have hence indicated in their guidelines [35] to assess ME. The estimated matrix effect (\% ME) on both the parabens and IS was found to be within $85 \%$ and $115 \%$ [39]. Table 3 shows\% ME on the parabens and the IS, and clearly indicates that there is no major ion suppression or enhancement on these analytes. The SPE sample clean-up method did help to minimize this effect. 
Table 1. Precision and accuracy data for methyl paraben.

\begin{tabular}{|llll|}
\hline $\begin{array}{l}\text { Concentration } \\
\text { (ng/ml) }\end{array}$ & \multicolumn{2}{c}{ Precision } & Accuracy \\
\cline { 2 - 3 } Interday & Mean \pm SD & $\%$ RSD (CV) \\
\hline 20 (LOQ) & $19.4 \pm 0.5$ & 2.5 & 97.2 \\
\hline 40 (LQC) & $40.1 \pm 1.1$ & 2.7 & 100.3 \\
\hline 200 (MQC) & $196.6 \pm 6.6$ & 3.4 & 98.3 \\
\hline 800 (UQC) & $790.7 \pm 8.7$ & 1.1 & 98.8 \\
\hline Intraday & & & \\
\hline 20 (LOQ) & $18.3 \pm 1.5$ & 0.08 & 91.5 \\
\hline 40 (LQC) & $42.4 \pm 4.2$ & 0.1 & 106.1 \\
\hline 200 (MQC) & $206.0 \pm 17.8$ & 0.09 & 103.0 \\
\hline $800($ UQC) & $768.6 \pm 15.8$ & 0.05 & 96.0 \\
\hline
\end{tabular}

Stability

Stock solution

The stock solution of parabens was stable for 6 months in methanol at $4^{\circ} \mathrm{C}$ and for $24 \mathrm{~h}$ at room temperature.

\section{DBS samples}

Spiked DBS stored at $-20^{\circ} \mathrm{C}$ for the period of $24 \mathrm{~h}, 1$, 3, 6 months and 1 year showed values comparable with freshly prepared samples.

\section{Blood plasma partitioning of parabens}

For both methyl and propyl parabens, the blood to plasma partitioning ratio $\left(\mathrm{K}_{\mathrm{RBC} / \mathrm{PL}}\right)$ was calculated to be 1.0 based on the formula mentioned in methods section. Therefore, both the parabens distributed equally in RBC and plasma. Hence, both whole blood (in our case DBS samples) and plasma (not applicable in our study) could have been used for sampling.

\begin{tabular}{|c|c|c|c|}
\hline \multirow{2}{*}{$\begin{array}{l}\text { Concentration } \\
(\mathrm{ng} / \mathrm{ml})\end{array}$} & \multicolumn{2}{|c|}{ Precision } & \multirow[t]{2}{*}{ Accuracy } \\
\hline & Mean \pm SD & $\%$ RSD (CV) & \\
\hline \multicolumn{4}{|l|}{ Interday } \\
\hline 20 (LOQ) & $19.7 \pm 0.9$ & 4.3 & 98.4 \\
\hline 40 (LQC) & $39.6 \pm 0.4$ & 1.1 & 99.1 \\
\hline 200 (MQC) & $196.0 \pm 4.9$ & 2.5 & 98.0 \\
\hline 800 (UQC) & $823.0 \pm 18.9$ & 2.3 & 102.9 \\
\hline \multicolumn{4}{|l|}{ Intraday } \\
\hline 20 (LOQ) & $18.0 \pm 2.7$ & 0.14 & 94.6 \\
\hline 40 (LQC) & $40.8 \pm 2.8$ & 0.07 & 101.9 \\
\hline 200 (MQC) & $197.8 \pm 18.4$ & 0.09 & 98.9 \\
\hline 800 (UQC) & $824.8 \pm 21.1$ & 0.02 & 103.1 \\
\hline
\end{tabular}

Sample collection from the patients, hematocrit \& application of the analytical method to the ESNEE clinical study

The blood taken from the neonates was mostly from heel pricks which was accurately measured using a fixed volume $15 \mathrm{ml}$ capillary device and transferred to the cards. Only two to three spots were available (in some instances only one spot was taken). To deal with the issue of the hematocrit, an $8 \mathrm{~mm}$ disk was punched from the card, wherein the whole spot was captured for analysis. This was based on Fan et al.'s findings [40] which discuss how to deal with the hematocrit issue especially with the variation expected in neonatal patient groups. Whole spot methods eliminate the variation from spreading and nonhomogeneity and allow for more consistent DBS concentrations, even at different hematocrit levels as long as the volume of the spotting is accurate. Zheng et al. [41] have also demonstrated that the whole spot approach was effective in eliminating the hematocrit effect for the analysis of apixaban in human DBS when an accurate blood sample volume was collected on DBS cards.

The validated method was applied to the analysis of the above clinical samples. A total of 927 DBS samples from 196 recruited patients (neonates) were analyzed. Parent(s) or guardian(s) of all eligible patients gave informed verbal and written consent. Opportunistic sampling was used to collect samples from each patient, wherein a tiny amount of sample was taken while the bloods were done for routine laboratory analysis. Figure 2 represents a chromatogram of a preterm neonate, 21 days old, $1.5 \mathrm{~kg}$ in weight at a sampling time of $16 \mathrm{~h}$ postdose of a pediatric formulation containing parabens. The concentrations obtained from the patient sample analysis from each hospital site are shown in the Figure 3. The hospitals who participated in this study were Chester, Leighton (LTGN), LWH (Liverpool Women's Hospital) and Arrowe Park from UK and University of Tartu hospital from Estonia. Only $40 \%$ of MPB and 14\% PPB samples yielded the concentrations above the LOQ $(20 \mathrm{ng} / \mathrm{ml})$. This primarily reflects the low amounts of MPB and PPB excipients present in pharmaceutical formulations, typically $0.1-0.2 \% \mathrm{w} / \mathrm{v}$ and $0.02 \% \mathrm{w} / \mathrm{v}$, respectively. It could also reflect rapid metabolism of the parabens [42] in both the gastrointestinal tract and liver.

\section{Conclusion}

The aim of the ESNEE was to develop excipient kinetic EK models for selected excipients in neonates. Relatively very few of the medicines administered to neonates are tested in this age group. There is little previous work on the exposure and safety of the excipients within the neonatal population. Hence, to study the 
EK, we needed to measure the concentration of each excipient in the bloodstream of the neonates. We chose a few excipients which are commonly used in these formulations (mainly parabens and ethanol). These were then analyzed in different laboratories within our consortium. Our laboratory was involved in developing and analyzing parabens from the DBS. This analytical data were then used to model EK for parabens which has been reported elsewhere [43].

Herein we report a simple, quantitative LC-MS/MS DBS parabens assay, which has been successfully developed, validated and applied to analyze neonatal samples. The circulating blood concentrations of parabens in neonates confirm systemic exposure to these compounds following administration of routine medicines. We report the first clinical study of systemic PB exposure in neonates. Only $40 \%$ of $\mathrm{MPB}$ and $14 \% \mathrm{PPB}$ samples yielded the concentrations above the LOQ (20 ng/ml). This analytical data have now been subjected to population EK modeling. The clinical study of parabens among the children who received parabens in routinely administered medicines showed that the circulating concentrations of MPB are not sufficient to sustain concerns about long-term outcomes. PPB
Table 3. Matrix effect.

\begin{tabular}{|llll|}
\hline \multirow{2}{*}{ Concentrations $(\mathrm{ng} / \mathrm{ml})$} & \multicolumn{3}{c|}{ Matrix effect (\%) } \\
\cline { 2 - 4 } 20 (LOQ) & MPB & PPB & IS (5 ng/ml) \\
\hline $200($ MQC) & 98.4 & 96.9 & 94.6 \\
\hline 800 (UQC) & 103.4 & 97.5 & \\
\hline
\end{tabular}

was below the limit of detection in half the children studied. This provides reassurance to clinicians, since the circulating concentrations are low and any metabolites are unlikely to have any endocrine disrupting effects [44].

\section{Future perspective}

DBS sampling and analysis has evolved fast in the last decade. With the increase of sensitivity of the new mass spectrometers, the DBS technology will be widely accepted by the academics and the industry as a very important sampling method. Those involved in animal research could reduce the number of animals used to a minimum, to obtain information from fewer animals or more information from the same number of animals by using the DBS technology. In our own work in the field

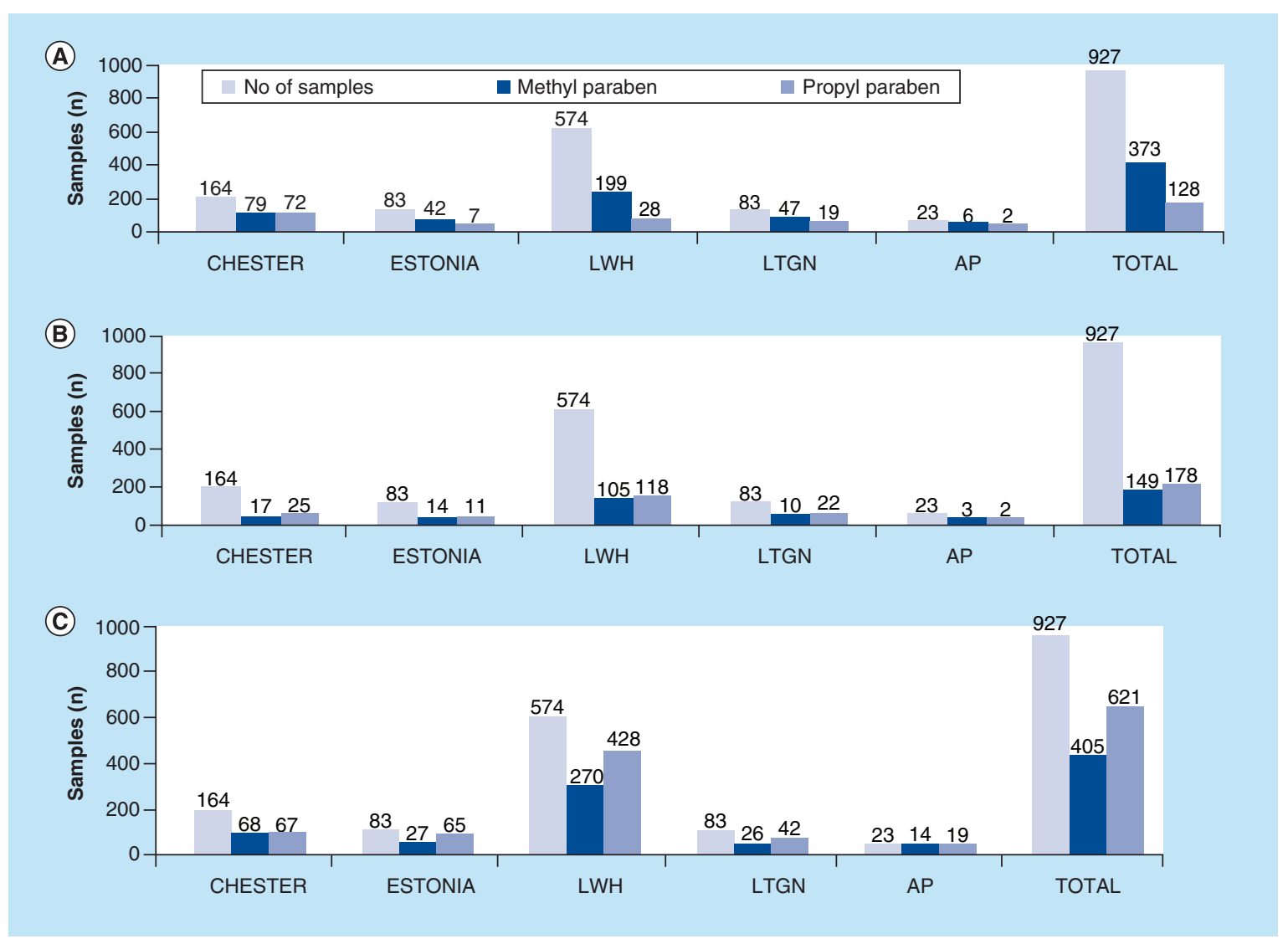

Figure 3. Concentrations obtained from the patient sample analysis from each hospital site. (A) Concentrations above LOQ (20 ng/ml); (B) concentrations between 10 and $19 \mathrm{ng} / \mathrm{ml}$. (C) Concentrations below limit of detection $(10 \mathrm{ng} / \mathrm{ml})$. 
of pediatric research, this technology has been and will be very useful in future. To the specifics of our research in excipients - more excipients (commonly used in pediatric formulations) should be studied for their safe use. This could be done using existing expertise within Europe with the co-ordination with EMA and the pharmaceutical companies, by doing a multicenter trial.

\section{Acknowledgements}

The authors would like to thank A Smith, K Harvey, S Graham (LWH) and other members of the neonatal research teams in the UK. We would also thank the team in Estonia (I Lutsar, T Metsvaht, H Varendi and G Nellis) who collected and provided us the precious samples and also contributed to the conduct of this study. We would also like to thank all the parents and children who participated in this multi-centre trial. The main author $\mathrm{S}$ Yakkundi is now based at the INFANT Centre, Metabolomics Group, Mass Spectrometry laboratory, Cork University Maternity Hospital, UCC, Cork, Ireland.

Financial \& competing interests disclosure

The work described here was funded under ERA-NET PRIOMEDCHILD programme. In the UK, this was funded by
MRC Grant G1100158 to the Principal Investigator (MA Turner). The authors have no other relevant affiliations or financial involvement with any organization or entity with a financial interest in or financial conflict with the subject matter or materials discussed in the manuscript apart from those disclosed.

No writing assistance was utilized in the production of this manuscript.

\section{Ethical conduct of research}

The authors state that they have obtained appropriate institutional review board approval or have followed the principles outlined in the Declaration of Helsinki for all human or animal experimental investigations. In addition, for investigations involving human subjects, informed consent has been obtained from the participants involved.

\section{Open access}

This article is distributed under the terms of the Creative Commons Attribution License 4.0 which permits any use, distribution, and reproduction in any medium, provided the original author(s) and the source are credited. To view a copy of the license, visit http://creativecommons.org/licenses/by/4.0/

Executive summary

- Measurement of methyl and propyl parabens concentrations from DBS by LC-MS/MS.

- DBS sampling was used to collect opportunistic blood samples $(15 \mu \mathrm{l})$ from the neonates who have been administered parabens containing formulations.

- One hundred and ninty-six neonates were recruited from four UK and one Estonian site; a total of 927 DBS samples were available for analysis.

- This study addresses the systemic exposure of parabens to the neonatal population.

\section{References}

Papers of special note have been highlighted as:

- of interest; $\bullet$ of considerable interest

1 European Food Safety Authority EFSA (2004). www.efsa.europa.eu/en/press/news/afc040929

-• Acceptable daily intake of parabens.

2 Whittaker A, Currie AE, Turner MA, Field DJ, Mulla H, Pandya HC. Toxic additives in medication for preterm infants. Arch. Dis. Child Fetal Neonatal 94(4), F236-F240 (2009).

- This was one of the papers to initiate the ESNEE project.

3 European Medicines Agency EMEA/536810/2008 (2009). www.ema.europa.eu

- Justification for the use of the DBS sampling.

4 Emmons G, Rowland M. Pharmacokinetic considerations as to when to use dried blood spot sampling. Bioanalysis 2(11), 1791-1796 (2010).

5 Hindmarsh KW, John E, Asali LA, French JN, Williams GL, McBride WG. Urinary excretion of methylparaben and its metabolites in preterm infants. J. Pharm. Sci. 72(9), 1039-1041(1983).

-• One of the first publications to explain the concentration of methyl parabens in preterm infants.
6 Zotou A, Sakla I, Tzanavaras PD. LC-determination of five paraben preservatives in saliva and toothpaste samples using UV detection and a short monolithic column. J. Pharm. Biomed. Anal. 53(3), 785-789 (2010).

7 Silva GH, Bottoli CB, Groppo FC et al.. Methylparaben concentration in commercial Brazilian local anesthetics solutions. J. Appl. Oral Sci. 20(4), 444-448 (2012).

8 Byrne J, Velasco-Torrijos T, Reinhardt R. Development and validation of a novel stability-indicating HPLC method for the simultaneous assay of betamethasone-17-valerate, fusidic acid, potassium sorbate, methylparaben and propylparaben in a topical cream preparation. J. Pharm. Biomed. Anal. 96, 111-117 (2014).

9 Hewala I, El-Fatatry H, Emam E, Mabrouk M. Development and application of a validated stability-indicating highperformance liquid chromatographic method using photodiode array detection for simultaneous determination of granisetron, methylparaben, propylparaben, sodium benzoate, and their main degradation products in oral pharmaceutical preparations. J. AOAC Int. 94(5), 1447-1460 (2011).

10 Darbre PD, Aljarrah A, Miller WR, Coldham NG, Sauer MJ, Pope GS. Concentrations of parabens in human breast tumours. J. Appl. Toxicol. 24(1), 5-13 (2004). 
11 Lee MR, Lin CY, Li ZG, Tsai TF. Simultaneous analysis of antioxidants and preservatives in cosmetics by supercritical fluid extraction combined with liquid chromatography-mass spectrometry. J. Chromatogr. A 1120(1), 244-251 (2006).

12 Ye X, Kuklenyik Z, Bishop AM, Needham LL, Calafat AM. Quantification of the urinary concentrations of parabens in humans by on-line solid phase extraction-high performance liquid chromatography-isotope dilution tandem mass spectrometry. J. Chromatogr. B Analyt. Technol. Biomed. Life Sci. 844(1), 53-59 (2006).

13 Ye X, Bishop AM, Needham LL, Calafat AM. Automated on-line column-switching HPLC-MS/MS method with peak focusing for measuring parabens, triclosan, and other environmental phenols in human milk. Anal. Chim. Acta 622(1), 150-156 (2008).

14 Frederiksen H, Jørgensen N, Andersson AM. Parabens in urine, serum and seminal plasma from healthy Danish men determined by liquid chromatography-tandem mass spectrometry (LC-MS/MS). J. Exp. Sci. Environ. Epidemiol. 21(3), 262-271 (2011).

15 Jiménez-Díaz I, Vela-Soria F, Zafra-Gómez A et al. A new liquid chromatography-tandem mass spectrometry method for determination of parabens in human placental tissue samples. Talanta 84(3), 702-709 (2011).

16 Wang L, Wu Y, Zhang W, Kannan K. Characteristic profiles of urinary p-hydroxybenzoic acid and its esters (parabens) in children and adults from the United States and China. Environ. Sci. Technol. 47(4), 2069-2076 (2013).

17 Vela-Soria F, Ballesteros O, Rodríguez I et al. A new treatment by dispersive liquid-liquid microextraction for the determination of parabens in human serum samples. Anal. Bioanal. Chem. 405(23), 7259-7267 (2013).

18 Asimakopoulos AG, Wang L, Thomaidis NS, Kannan K. A multi-class bioanalytical methodology for the determination of bisphenol A diglycidyl ethers, p-hydroxybenzoic acid esters, benzophenone-type ultraviolet filters, triclosan, and triclocarban in human urine by liquid chromatographytandem mass spectrometry. J. Chromatogr. A 1324, 41-148 (2014).

19 Dewalque L, Pirard C, Dubois N, Charlier C. Simultaneous determination of some phthalate metabolites, parabens and benzophenone- 3 in urine by ultra high pressure liquid chromatography tandem mass spectrometry. J. Chromatogr. B Analyt. Technol. Biomed. Life Sci. 949-950, 37-47 (2014).

20 Zhao Y, Liu G, Shen $\mathrm{H}$ et al. Bioanalysis of propylparaben and p-hydroxybenzoic acid, and their sulfate conjugates in rat plasma by liquid chromatography-tandem mass spectrometry. J. Chromatogr. B Analyt. Technol. Biomed. Life Sci. 947-948, 68-74 (2014).

21 Rodríguez-Gómez R, Roldán-Pijuán M, Lucena R et al. Stir-membrane solid-liquid-liquid microextraction for the determination of parabens in human breast milk samples by ultra high performance liquid chromatography-tandem mass spectrometry. J. Chromatogr. A 1354, 26-33 (2014).

22 Myridakis A, Balaska E, Gkaitatzi C, Kouvarakis A, Stephanou EG. Determination and separation of bisphenol A, phthalate metabolites and structural isomers of parabens in human urine with conventional high-pressure liquid chromatography combined with electrospray ionisation tandem mass spectrometry. Anal. Bioanal. Chem. 407(9), 2509-2518 (2015).

23 Farajzadeh MA, Khosrowshahi EM, Khorram P. Simultaneous derivatization and air-assisted liquid-liquid microextraction of some parabens in personal care products and their determination by GC with flame ionization detection. J. Sep. Sci. 36(21), 3571-3578 (2013).

24 Lima Gomes PC, Barnes BB, Santos-Neto ÁJ, Lancas FM, Snow NH. Determination of steroids, caffeine and methylparaben in water using solid phase microextractioncomprehensive two dimensional gas chromatography-time of flight mass spectrometry. J. Chromatogr. A 1299, 126-130 (2013).

25 Ramírez N1, Borrull F, Marcé RM. Simultaneous determination of parabens and synthetic musks in water by stir-bar sorptive extraction and thermal desorption-gas chromatography-mass spectrometry. J. Sep. Sci. 35(4), 580-588 (2012).

26 Wang PG, Zhou W. Rapid determination of parabens in personal care products by stable isotope GC-MS/MS with dynamic selected reaction monitoring. J. Sep. Sci. 36(11), 1781-1787 (2013).

27 Guthrie R, Susi A. A Simple phenylalanine method for detecting phenylketonuria in large populations of newborn infants. Pediatrics 32, 338-343 (1963).

- The first publication to demonstrate the use of DBS in infants.

28 Edelbroek PM, van der Heijden J, Stolk LM. Dried blood spot methods in therapeutic drug monitoring: methods, assays, and pitfalls. Ther. Drug Monit. 31(3), 327-336 (2009).

29 Li W1, Tse FL. Dried blood spot sampling in combination with LC-MS/MS for quantitative analysis of small molecules. Biomed. Chromatogr. 24(1), 49-65 (2010).

30 Suyagh MF, Kole PL, Millership J, Collier P, Halliday H, McElnay JC. Development and validation of a dried blood spot-LC-APCI-MS assay for estimation of canrenone in paediatric samples. J. Chromatogr. B Analyt. Technol. Biomed. Life Sci. 878(9), 769-776 (2010).

31 Suyagh MF, Iheagwaram G, Kole PL et al. Development and validation of a dried blood spot-HPLC assay for the determination of metronidazole in neonatal whole blood samples. Anal. Bioanal. Chem. 397(2), 687-693 (2010).

32 Yakkundi S, Millership J, Collier P, Shields MD, McElnay J. Development and validation of a dried blood spot LCMS/MS assay to quantify ranitidine in paediatric samples. J. Pharm. Biomed. Anal. 56(5), 1057-1063 (2011).

33 Shah NM, Hawwa AF, Millership JS, Collier PS, McElnay JC. A simple bioanalytical method for the quantification of antiepileptic drugs in dried blood spots. J. Chromatogr. $B$ Analyt. Technol. Biomed. Life Sci. 923-924, 65-73 (2013).

34 Hawwa AF, Albawab A, Rooney M, Wedderburn LR, Beresford MW, McElnay JC. A novel dried blood spotLCMS method for the quantification of methotrexate polyglutamates as a potential marker for methotrexate use in children. PLoS ONE 9(2), e89908 (2014). 
35 US Department of Health and Humans Services, Food and Drug Administration. Center for Drug Evaluation and Research (CDER), Guidance for Industry, Bioanalytical Method Validation (2001).

www.fda.gov/downloads/Drugs/Guidance/ucm070107.pdf

- Guidelines used for method validation.

36 Yu S, Li S, Yang H, Lee F, Wu JT, Qian MG. A novel liquid chromatography/tandem mass spectrometry based depletion method for measuring red blood cell partitioning of pharmaceutical compounds in drug discovery. Rapid Commun. Mass Spectrom 19(2), 250-254 (2005).

-• Protocol followed for drug partitioning.

37 Vogeser M, Zachoval R, Spöhrer U, Jacob K. Potential lack of specificity using electrospray tandem-mass spectrometry for the analysis of mycophenolic acid in serum. Ther. Drug Monit. 23(6), 722-724 (2001).

- Insource fragmentation of drug metabolites.

38 Yan Z, Caldwell GW, Jones WJ, Masucci JA. Cone voltage induced in-source dissociation of glucuronides in electrospray and implications in biological analyses. Rapid Commun. Mass. Spectrom. 17(13), 1433-1442 (2003).

- Insource fragmentation of drug metabolites (glucuronides).

39 Chambers E, Wagrowski-Diehl DM, Lu Z, Mazzeo JR. Systematic and comprehensive strategy for reducing matrix effects in LC/MS/MS analyses. J. Chromatogr. B Analyt. Technol. Biomed. Life Sci. 852(1), 22-34 (2007).

40 Fan L, Lee JA. Managing the effect of hematocrit on DBS analysis in a regulated environment. Bioanalysis 4(4), 345-347 (2012).

- Hematocrit and whole spot capture.

41 Zheng N, Yuan L, Ji QC et al. "Center punch" and "whole spot" bioanalysis of apixaban in human dried blood spot samples by UHPLC-MS/MS. J. Chromatogr. B Analyt. Technol. Biomed. Life Sci. 988, 66-74 (2015).

- Hematocrit and whole spot capture.

42 Abbas S, Greige-Gerges H, Karam N, Piet MH, Netter P, Magdalou J. Metabolism of parabens (4-hydroxybenzoic acid esters) by hepatic esterases and UDP-glucuronosyltransferases in man. Drug Metab. Pharmacokinet. 25(6), 568-577 (2010).

43 Mulla H, Yakkundi S, McElnay J et al. An observational study of blood concentrations and kinetics of methyl- and propyl-parabens in neonates. Pharm. Res. 32(3), 1084-1093 (2015).

- Publication of the EK data based on the above analytical data.

44 European Medicines Agency, EMA/CHMP/ SWP/272921/2012.

www.ema.europa.eu 